\title{
The visual suffix effect in tests of the visual short-term store
}

\author{
ROBERT W. FRICK \\ University of Colorado, Boulder, Colorado
}

(Alice F. Healy, Sponsor)

Adding a visual suffix to the far left of a simultaneous visual presentation impairs recall in a variety of situations testing the visual short-term store.

The existence of a visual short-term store seems to be well accepted. For example, Baddeley's model of working memory (e.g., Baddeley, 1986) posits a visuospatial sketchpad. The visual short-term store can be differentiated from the auditory short-term store in that it retains a visual/spatial representation rather than an auditory representation. It can be differentiated from iconic memory in that its decay rate is slower, its capacity is more limited, it cannot be masked, and its contents are not tied to a particular spatial location (Phillips, 1974).

Presenting items visually is not sufficient to elicit use of this visual short-term store, because subjects can recode verbal items into an auditory format (Conrad, 1964). One methed of preventing auditory recoding is to use nonverbal stimuli. A second method is to present items too quickly to be subvocalized. Sperling (1960) noted that, with presentation times longer than approximately $50 \mathrm{msec}$, presentation time is not a critical factor, suggesting that performance is limited by the capacity of a short-term store rather than by perceptual factors. Evidence suggests that this store is the visual short-term store (Bongartz \& Scheerer, 1976; Coltheart, 1972; Wolford \& Hollingsworth, 1974). Thus, a presentation in the range of approximately 200 to $500 \mathrm{msec}$ should be long enough to avoid perceptual difficulties and short enough to prevent significant auditory recoding.

A third method of preventing auditory recoding is to require the subjects to engage in repetitive speech during the visual presentation (e.g., Murray, 1967). When the items are presented simultaneously and subjects are required to engage in articulatory suppression, use of the visual short-term store is elicited, even for 3- to 4-sec presentations (Frick, 1985).

Using fast visual presentations or slower simultaneous visual presentations with articulatory suppression, one can find several phenomena in visual short-term memory that

This research was supported by NIMH Training Grant MH-1461711 to the University of Colorado. Reprint requests should be sent to Robert Frick, Department of Psychology, SUNY at Stony Brook, Stony Brook, NY 11794-2500. are analogous to phenomena in auditory short-term memory. One of these is recency: Just as there is an improved recall of the last item of an auditory presentation, there is an improved recall of the last (far right) item in tests of the visual short-term store (Frick, 1988). A second analogous phenomenon is the suffix effect. Adding an extraneous item that the subject need not recall (called a suffix) to the end of an auditory presentation impairs recall (Crowder \& Morton, 1969; Dallett, 1965). Similarly, adding a suffix to the end (far right) of a visual presentation impairs recall in tests of the visual short-term store (Frick \& De Rose, 1986a, 1986b; Kahneman, 1973; Kahneman \& Henik, 1977). Frick and De Rose suggested that people are unable to prevent the suffix from entering their visual short-term store, so the suffix uses some of the limited capacity of that store.

Greene (1987) investigated the effect of a visual suffix in a variety of different situations, some of which (Experiments 1-4) would not have elicited use of the visual short-term store and hence are not relevant to this article. However, Greene also considered the role of the visual suffix in tests of the visual short-term store, disagreeing with Frick and De Rose's interpretation. Greene first argued that, in a 200 -msec presentation, subjects might not have time to identify all of the items, and, hence, valuable resources would be wasted on identifying the suffix. A problem with Greene's argument is, as already noted, immediate ordered recall of a brief visual presentation apparently is not limited by the time available for identifying the items. Therefore, the small amount of time spent identifying the suffix should not impair recall.

Greene offered three different points concerning the visual suffix effect found with longer simultaneous visual presentations and articulatory suppression (Frick \& De Rose, 1986a, 1986b). First, he questioned whether Frick and De Rose's findings would generalize to supraspan lists. Because Greene failed to replicate the visual suffix effect with both six- and nine-digit presentations, this point seems moot.

Second, Greene noted that the auditory suffix effect is typically defined as the selective impairment of the last 
few items of the presentation. Frick and De Rose did not report serial position curves, so their data might not have conformed to this pattern.

Finally, Greene noted that, in Frick and De Rose's experiments, the number of items to be recalled varied from trial to trial. For example, on one trial, the seventh item might be a suffix, and, on the next trial, the seventh item might be a to-be-recalled item. Greene suggested that this procedure might not be a fair test of the suffix effect, because, unless the subject kept very careful track of how many items were going to be presented for recall, there would be no way of knowing whether or not to report the suffix without first analyzing it.

Greene empirically investigated the effect of a visual suffix in three different situations that might be expected to test the visual short-term store. In his Experiment 5, nine items were presented for $1.2 \mathrm{sec}$, and articulatory suppression was not used. Greene found no visual suffix effect. It seems unlikely that the subjects could have subvocalized all of the items in $1.2 \mathrm{sec}$, although a subvocalization of at least some of the items would have been possible.

In Experiment 6, Greene presented nine items for $1.2 \mathrm{sec}$ and used articulatory suppression. Again, there was no suffix effect. However, recall of the ending items was near chance (approximately $24 \%$ ). The suffix would not be expected to impair recall of an item that was not in the visual short-term store.

Finally, in Experiment 7, Greene tested recall of six items presented for $1.2 \mathrm{sec}$ with articulatory suppression. Again, there was no suffix effect. The latter finding most strongly challenges the claims of Frick and De Rose, because it avoids the possible contamination of either subvocalization or a floor effect. Greene also found no recency in the no-suffix condition, contrary to the report by Frick (1988).

The present Experiment 1 tested the hypothesis that, when a constant number of to-be-recalled items is presented, a visual suffix will not impair recall. The procedure from Frick and De Rose's (1986b) Experiment 1 was followed closely, except that the number of to-be-recalled items presented on each trial was held constant.

\section{EXPERIMENT 1}

\section{Method}

Procedure. In brief, seven to-be-recalled digits were presented simultaneously for $3.5 \mathrm{sec}$ in the middle of a CRT. The subject repeated the phrase "A,B,C,D" while the digits were being presented. When the presentation disappeared, the subject attempted to recall the digits in order from left to right. The subject was instructed to use a visual memory to perform this task. For one block of 13 trials, there was no suffix; for the other block of 13 trials, the to-be-recalled digits were followed by the digit 3 . The digit 3 was never included in the to-be-recalled digits, the subjects were warned about the occurrence of the 3 , and they were told that they did not have to pay attention to the 3 and that they were not to recall the 3 . The first trial of each block was a practice trial.

Further details of the methodology can be found in Frick and De Rose (Experiment 1, 1986b).

Subjects. Ten students from introductory psychology classes at the University of Colorado participated to fulfill part of a course requirement.

\section{Results and Discussion}

The report of a digit was scored as correct only when that digit was recalled in the correct serial position. Serial position curves for the suffix and no-suffix conditions are presented in Figure 1.

There are several potential indications of the suffix effect: impaired recall of the last digit, impaired recall of all digits, and a decreased probability of recalling the entire sequence of digits correctly. Because these three measures agreed in all of the experiments reported in this article, and because the impairment upon the last digit usually is the most sensitive indication of the suffix effect, only this measure will be reported. Thus, the size of the suffix effect will be defined as the percentage recall of the last digit in the no-suffix condition minus percentage recall of the last digit in the suffix condition. In Experiment 1 , there was a suffix effect of $32 \%[t(9)=5.23$, $p<.001]$.

Recency was defined as the percentage recall of the last digit minus the percentage recall of the next-to-last digit. There was a recency effect of $17 \%$ in the no-suffix condition $[t(9)=5.16, p<.001]$.

These results failed to replicate Greene's in two ways: There was recency in the no-suffix condition, and there was a suffix effect. Thus, the presence of the suffix effect in the studies by Frick and De Rose cannot be attributed to the fact that the number of to-be-recalled items had been varied.

\section{EXPERIMENT 2}

Unfortunately, the results of Experiment 1 did not reveal why Greene did not find a visual suffix effect. A series of experiments was performed, systematically manipulating individual variables, in an attempt to discover a method of eliminating the visual suffix effect in tests of the visual short-term store.

In one experiment, a zero was used as the suffix; in a second experiment, the subjects articulated "la" as quickly as possible. These were procedures Greene had

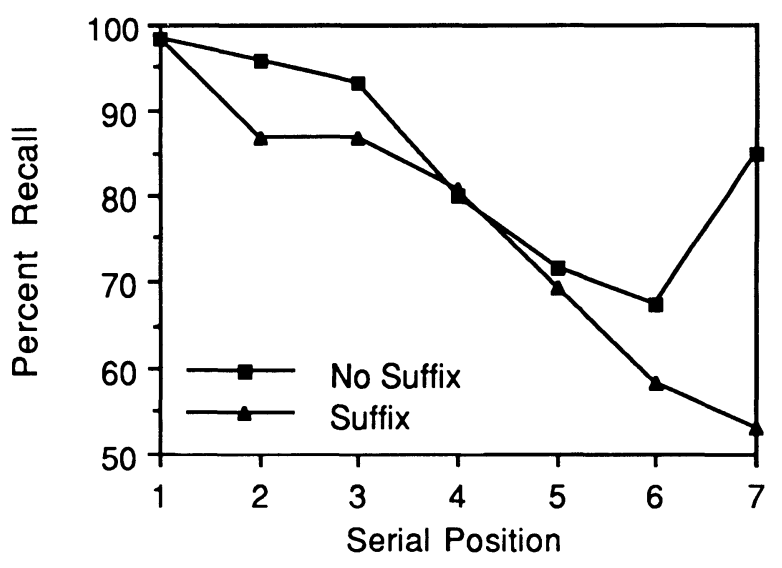

Figure 1. Serial position curves for the suffix and no-suffix conditions in Experiment 1. 
used in his study. A third experiment investigated written report. In a fourth experiment, an attempt was made to induce the subjects not to use their visual short-term store. The subjects were given no instructions to remember a picture of the stimuli. Testing began with sequential presentations, to induce auditory recoding, then was switched to simultaneous presentations, and was finally switched to simultaneous presentations with articulatory suppression. None of these manipulations was successful, in that there was always a statistically significant recency and there was always a statistically significant suffix effect.

In a final attempt to produce a lack of visual suffix effect, the procedures of Greene's Experiment 7 were followed as closely as possible. The computer disk used for that experiment was lost or destroyed (Greene, personal communication, January 1988), so it was not possible to replicate that experiment in all regards, but it was possible to replicate that experiment in the details described in his article.

Several of Greene's procedures (e.g., intermixing trials with a suffix and trials without a suffix, or presenting the digits for only $1.2 \mathrm{sec}$ ) might be expected to enhance the effect of the suffix. However, there were three aspects of his procedure that possibly might reduce the suffix effect. First, digits were never repeated in a digit string. This lack of repetition might increase the chance of correctly guessing the last digit, in which case an impaired memory for the last digit might be more difficult to detect.

Second, Greene's zero suffix presumably had a diagonal line, as a computer displays a zero. Not much is known about the effects of various types of suffixes, and it is possible that this suffix might not create a suffix effect.

Third, in addition to testing trials with articulatory suppression, Greene also tested trials without articulatory suppression. The possible use of the auditory short-term store on these trials might have had some effect upon the subjects' strategy on the trials with articulatory suppression. The presence of this condition also doubled the number of trials and, hence, increased the amount of practice with and without a suffix.

\section{Method}

The method followed that of Greene (1987, Experiment 7), with 16 subjects. In addition to the changes noted above from Experiment 1, the digits were presented at the top of the CRT, and only six to-be-recalled digits were presented.

\section{Results and Discussion}

The results of this experiment are presented in Table 1. When articulatory suppression was present, there was a recency of $4 \%$ in the no-suffix condition $[t(15)=3.16$, $p<.01]$ and a suffix effect of $18 \%[t(15)=3.47, p<$ $.01]$. When articulatory suppression was not present, there was still a recency of $4 \%$ in the no-suffix condition $[t(15)=2.45]$ and a suffix effect of $10 \%[t(15)=3.13$, $p<.01]$.
Table 1

Percentage Recall by Serial Position in Experiment 2

\begin{tabular}{|c|c|c|c|c|c|c|c|}
\hline \multirow[b]{2}{*}{ Condition } & \multicolumn{7}{|c|}{ Serial Position } \\
\hline & 1 & 2 & 3 & 4 & 5 & 6 & 7 \\
\hline \multicolumn{8}{|c|}{ Six Digits Presented } \\
\hline \multicolumn{8}{|l|}{ Silent } \\
\hline No Suffix & 99 & 98 & 97 & 94 & 93 & 97 & \\
\hline Suffix & 97 & 95 & 96 & 91 & 88 & 87 & \\
\hline \multicolumn{8}{|l|}{ Suppression } \\
\hline No Suffix & 98 & 98 & 95 & 92 & 89 & 93 & \\
\hline Suffix & 98 & 90 & 92 & 86 & 79 & 76 & \\
\hline \multicolumn{8}{|c|}{ Seven Digits Presented } \\
\hline \multicolumn{8}{|l|}{ Silent } \\
\hline No Suffix & 98 & 92 & 89 & 92 & 81 & 80 & 86 \\
\hline Suffix & 98 & 86 & 88 & 82 & 72 & 66 & 66 \\
\hline Suppression & & & & & & & \\
\hline No Suffix & 97 & 92 & 91 & 84 & 68 & 68 & 78 \\
\hline Suffix & 99 & 91 & 85 & 78 & 64 & 59 & 54 \\
\hline
\end{tabular}

Thus, even when Greene's procedures are followed as closely as possible, recency and the suffix effect can be found. The effects were not as large as in previous experiments, but they were still robust.

These results extend the lack of replication of Greene's negative effects to 1.2-sec presentations without articulatory suppression. It seems likely that when digits or letters are presented simultaneously and subjects are not required to engage in articulatory suppression, subjects will use a combination of the auditory short-term store and the visual short-term store (Frick, 1985). The relatively short presentation duration of $1.2 \mathrm{sec}$ may have interfered somewhat with the use of the auditory short-term store, forcing subjects to rely upon the visual short-term store more than they ordinarily might have. Thus, the suffix effect was found in this condition, although it was smaller.

In this experiment, the overall level of recall when articulatory suppression was present was higher than in Greene's study. His subjects recalled approximately $79 \%$ of the digits in the no-suffix condition and $78 \%$ of the digits in the suffix condition, whereas the subjects in this experiment recalled $94 \%$ of the digits in the no-suffix condition and $87 \%$ of the digits in the suffix condition. (The standard error of the mean for the latter two values was $1.4 \%$ and $2.3 \%$, respectively.)

To verify that the results of these experiments were not a consequence of the high levels of recall, Experiment 2 was replicated with a seven-digit presentation. The results are included in Table 1. The overall level of recall was lower. (With articulatory suppression, $83 \%$ of the digits were recalled in the no-suffix condition and $76 \%$ were recalled in the suffix condition.) Nonetheless, when articulatory suppression was present, there was a recency of $9 \%$ in the no-suffix condition $[t(15)=3.74, p<.01]$ and a suffix effect of $23 \%[t(15)=5.27, p<.001]$. When articulatory suppression was not present, there was a marginally significant recency of $6 \%$ in the no-suffix condition $[t(15)=1.74, p<.20]$ and a suffix effect of $20 \%[t(15)=5.22, p<.001]$. 


\section{GENERAL DISCUSSION}

The results of the present experiments differ from Greene's in three regards. Most importantly, there was a robust visual suffix effect in a variety of different conditions that would be expected to test the visual short-term store, including in a replication of the reported details of Greene's study. Second, there was a robust recency effect (improved recall of the far right digit) in the no-suffix condition. Finally, the overall level of recall was higher.

The most likely explanation of the discrepancy between these results and Greene's seems to be that the subjects in Greene's study were not using their visual short-term store. This would account for the lack of a suffix effect, the lack of recency in the no-suffix condition, and the lower level of recall. However, there is no obvious reason why Greene's subjects would not have used their visual short-term store. Differences in subject populations cannot be ruled out. However, there did not seem to be any individual differences in susceptibility to the visual suffix effect in the present experiments. If the conditions with no articulatory suppression are ignored, and if the visual suffix is defined as occurring when errors on the last digit are made more often in the suffix condition than in the no-suffix condition, then $82 \%$ of the subjects in all of the experiments mentioned in this article showed the suffix effect, $15 \%$ of the subjects were neutral, and only $4 \%$ of the subjects showed a negative suffix effect.

The results of these experiments are consistent with the claim (Frick \& De Rose, 1986a, 1986b) that people have limited control over the contents of their visual short-term store: They can choose which group of stimuli they want to enter their visual short-term store (with groups being defined by the Gestalt principles of grouping). However, they cannot choose to have just a part of a group enter their visual short-term store. In particular, subjects cannot decide to have the to-be-recalled items enter the visual short-term store while excluding a single suffix. Thus, the suffix enters the visual short-term store and impairs recall by using some of the limited capacity of that store.

\section{REFERENCES}

BAdDEley, A. D. (1986). Working memory. Oxford: Clarendon. BongarTZ, W., \& SCHEerer, E. (1976). Two visual stores and two processing operations in tachistoscopic partial report. Quarterly Journal of Experimental Psychology, 28, 203-219.

Coltheart, M. (1972). Visual information-processing. In P. C. Dodwell (Ed.), New horizons in psychology (Vol. 2, pp. 62-85). London: Penguin.

ConRad, R. (1964). Acoustic confusions in immediate memory. British Journal of Psychology, 55, 75-84.

Crowder, R. G., \& Morton, J. (1969). Precategorical acoustic storage (PAS). Perception \& Psychophysics, 5, 365-373.

DALLETT, K. M. (1965). "Primary memory": The effects of redundancy upon digit repetition. Psychonomic Science, 3, 237-238.

FRICK, R. W. (1985). Testing visual short-term memory: Simultaneous versus sequential presentations. Memory \& Cognition, 13, 346-356.

FRICK, R. W. (1988). Issues of representation and limited capacity in the visuospatial sketchpad. British Journal of Psychology, 79, 289-308.

Frick, R. W., \& DE Rose, A. (1986a). Attenuating the visual suffix effect with color. Memory \& Cognition, 14, 391-397.

Frick, R. W., \& DE Rose, A. (1986b). The suffix effect and preattentive unit-formation in visual short-term memory. Canadian Journal of Psychology, 40, 97-108.

GREENE, R. L. (1987). Stimulus suffixes and visual presentation. Memory \& Cognition, 15, 497-503.

Kahneman, D. (1973). Attention and effort. Englewood Cliffs, NJ: Prentice-Hall.

KAHNEMAN, D., \& HeniK, A. (1977). Effects of visual grouping on immediate recall and selective attention. In S. Dornic (Ed.), Attention and performance VI (pp. 307-332). Hillsdale, NJ: Erlbaum.

MURRAY, D. J. (1967). The role of speech responses in short-term memory. Canadian Journal of Psychology, 21, 263-276.

Phillips, W. A. (1974). On the distinction between sensory storage and short-term visual memory. Perception \& Psychophysics, 16, 283-290.

SPERLING, G. (1960). The information available in brief visual presentations. Psychological Monographs, 74, 1-29.

WOLFORD, G., \& HollingswORTH, S. (1974). Evidence that short-term memory is not the limiting factor in the tachistoscopic full-report procedure. Memory \& Cognition, 2, 796-800.

(Manuscript received August 14, 1989.) 